\title{
CHEMISTRY OF LEAF LITTER OF SOME AGRO-FORESTRY SPECIES IN SRI LANKA
}

\author{
M K T K Amarasinghe and R Senaratne \\ Faculty of Agriculture, University of Ruhuna.
}

Decomposition of leat bitcr is a major process in the nutricnt dynamics of agrocosystems. which is intrically govenod hy the litter chemistry. The chemistry of leaf litles determines both the lime course of decomposition and the nutrient release pattern. There are matny agroforestry species in Sri lankal. but information avaliahle on theif litter chemistry is

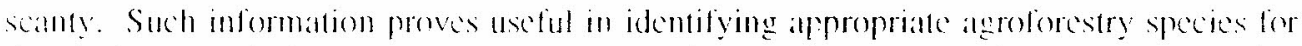
developing stestamable agrocosystems. Therefore studies were carried out fo determine

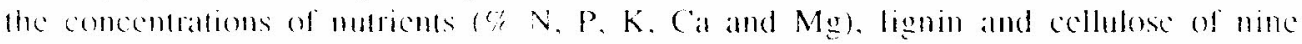

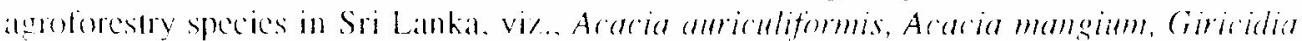

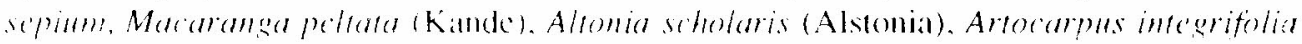

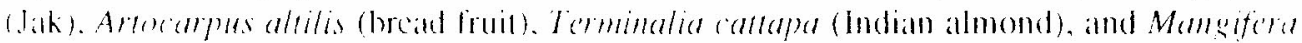
indires (mantero).

Considerable interspecilic variation in the above parancers was observed in the leat litter. As regards the per cents of X.P. K. Ca and Mg. has values observed varied from 0.395 1.02. (0.025- $0.171,(116-0.95,1.76-2.57$ and $0.22-0.51$, respectively. The highest

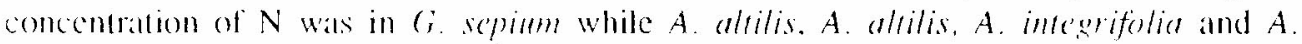
shours had the highest concentration of P, K. Ca and Mg. respectively. This underlines the importance of introducime diverse species (hiological diversity) in order to establish a halanced fertility regime. Mindira and $A$. mamgium had the highest concentration of lignin $(22.99 \%)$ and collulose $(32.76 \%)$. respeclively. A salient feature in the leat litter in M. indice was thath, it had the lowest concentration of $\mathrm{N}(0.395 \%)$ and cellulose $(14.59 \%)$ and the highest concentration ol lignin $(22.99 \%)$. These data prove useful in identifying a suitahle combinalion of agroforestry species for sustainable soil fertility management. 